\title{
Evolution of the soil water retention curve based on plastic volumetric strain
}

\author{
$J$. Kodikara and C. Jayasundara \\ Department of civil engineering, Monash University, Australia
}

\begin{abstract}
The water retention behaviour of soil can be defined as the relationship between the degree of saturation (or water content) and suction at a constant temperature, which characterises the hydraulic behaviour of unsaturated soils, normally represented as the soil water retention curve (SWRC). The SWRC is commonly measured at nominal net stress by initially saturating a soil specimen and then subjecting it to drying and wetting paths, resulting in major drying and wetting curves. However, there is evidence that during these major drying and wetting paths and initial saturation, soil can undergo volumetric deformation with changes in void ratio, sometimes plastically. Therefore, for coupling the SWRC with mechanical behaviour, the dependency of SWRC on other state variables such as void ratio has been proposed. In this paper, an approach to defining SWRC for a particular plastic volumetric strain is presented within the generalised MPK model. The SWRC evolves as soil is subjected to wet/dry cycles, eventually approaching drying and wetting curves relevant to an environmentally-stabilised state. The performance of this model is demonstrated by the simulation of the loading/unloading/drying/wetting paths followed in a laboratory experiment. In addition, the evolution of the commonly-considered major drying and wetting curves is simulated, highlighting key features of the environmentally-stabilised line..
\end{abstract}

\section{Introduction}

The soil water retention curve (SWRC) is considered an essential characteristic in unsaturated soil modelling $[1,2]$. It is commonly represented as a function of the volumetric water content ( ), gravimetric water content ( ), or degree of saturation ( ) with suction. In its early developments, SWRC for a particular soil sample was measured at a constant external stress, which in many cases is zero. The soil sample can be either a laboratorycompacted or consolidated soil specimen or a natural soil sample obtained from the field. If the soil is dried from a saturated state, it is considered to follow the drying curve of SWRC, commonly referred to as the primary drying curve [3]. When the soil is wetted back from an ovendried state, it is considered to follow the primary wetting curve. SWRC displays significant hysteresis, where, if drying is reversed to wetting, the soil follows a scanning curve first until it reaches the primary wetting curve and then follows it, or vice versa. It is sometimes considered that these two primary curves provide bounding surfaces for other hydraulic states of the soil [3]. It is argued that this description is not entirely consistent, since SWRC can vary as soils undergo deformation during wetting and drying subject to applied stresses.

Various researchers have endeavoured to consider the dependency of soil deformation or soil state on SWRC by incorporating governing variables. For instance, the SWRC has been coupled to the void ratio or specific volume [4, 5]; soil density [6], volumetric strain
[7], mean net stress [8] and volumetric plastic strain [9, 10]. Specifically, Gallipoli et al. [4] extended the Van Genuchten [11]-based SWRC as a function of specific volume in a study of compacted kaolin. Later, a void ratio-dependent hysteretic water retention model was developed by Morvan et al. [5] based on the concept of bounding surface plasticity.

Wheeler et al. [9] introduced a SWRC concept dependent on the plastic volumetric strain, where modified suction (= where is porosity and is suction) was used in place of suction. The modified suction was introduced for consistency with the work equation for unsaturated soils proposed by Houlsby (1997). Subsequently, Lloret-Cabot et al. [10], Lloret-Cabot et al. [12] reinforced this concept by defining SWRC as the relationship between and with supporting experimental evidence. More recently, Kodikara et al. [13] utilised the same approach in the MPK generalised model to capture the hydro-mechanical behaviour of unsaturated soils. In this paper, SWRC development in the MPK model is further elucidated, paying special attention to the evolution of the SWRC as soil moves from loose to dense states.

\section{MONASH-PERADENIYA-KODIKARA (MPK) generalised model}

A brief introduction to the MPK generalised model is given here. Figure 1 encapsulates the salient features of

Corresponding author: chathurika.jayasundara@monash.edu 
volumetric behaviour in the generalised MPK model in the space. The specific volume ( ) is represented as a function of specific water volume ( ) and net stress as the main independent stress state variable, while suction ( ) is regarded as a dependent variable. The main yield surface (also referred to as the loading-wetting state boundary surface (LWSBS - A - B - C - D) or virgin compaction surface) represents the loosest state (at nominal stress) the soil can reach volumetrically. The reference (zero) plastic volumetric strain is defined at Point B, loosest at saturation. When the saturated soil is consolidated to a certain, it can be used to define the corresponding unsaturated states. When soil is subjected to wet/dry cycles, it commonly reaches a stabilised state where the soil shrinks and swells elastically. This concept is used to define the gradient $\left(\left(\mathrm{d} v / \mathrm{d} v_{\mathrm{w}}\right)_{\mathrm{p}}\right)$ of the so-called volumetric elastic plane (VEP). The gradient in the stress direction is given by $(\mathrm{d} v / \mathrm{d} \ln (p))_{\mathrm{v}_{\mathrm{w}}}$ representing the unload/reload compression index $\left(k_{\mathrm{w}}\right)$.The intersection of this VEP with the LWSBS defines the LC curve corresponding to that particular plastic strain. For the same $\varepsilon_{v}^{\mathrm{p}}$, a corresponding SWRC is defined in the $S_{\mathrm{r}}, s^{*}$ plane to couple the hydraulic behaviour.

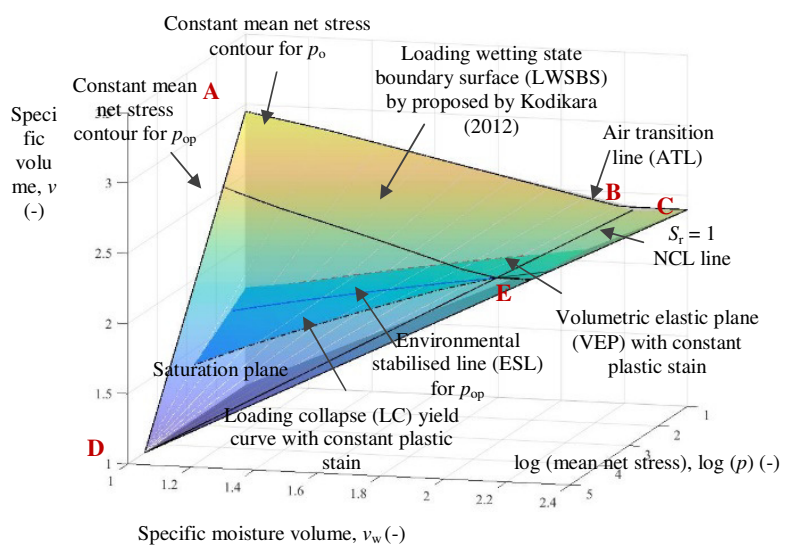

Fig. 1. MPK generalised model (adopted from [13])

Figure 2(a) depicts a 2-D representation of the LWSBS produced by the MPK model for a data set for compacted kaolin showing a series of constant net stress contours (from $50 \mathrm{kPa}$ to $500 \mathrm{kPa}$ ) and constant suction contours (from $50 \mathrm{kPa}$ to $1000 \mathrm{kPa}$ ), computed from the associated SWRCs. The general shape of the suction contours is consistent with some of the experimental evidence, including that of Tarantino and De Col [14]. It should be noted that these contours are on the yield surface, but when the soil is unloaded (for example, to the nominal stress plane), they show relatively vertical contours on the dry side of ATL and slant towards the saturated line (NCL), as shown in many publications [14].

Figure 2(b) shows the SWRC for a range of $\varepsilon_{\mathrm{v}}^{\mathrm{p}} \mathrm{s}$ for the same soil. The evolution of the SWRC is as follows. When the soil is loose and dry (at Point L), the corresponding suction is considered to be very high and is represented by a single point as SWRC (Point L). As the soil state traverses from $\mathrm{L}$ to (for instance) $\mathrm{P}$ by wetting at nominal stress, $\varepsilon_{v}^{\mathrm{p}}$ accumulates, generating a series of partial SWRCs, as the figure shows. The first SWRC results when the soil state reaches full saturation at Point C. The other two SWRCs are given for subsequent yielding for $\varepsilon_{\mathrm{v}}^{\mathrm{p}}$ s. More details of this evolution are presented later.

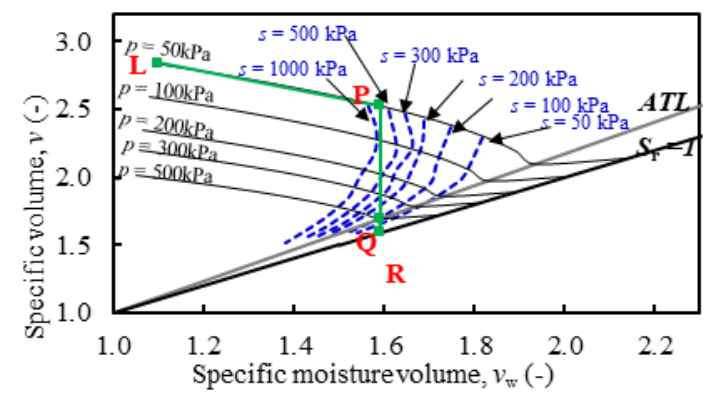

(a)

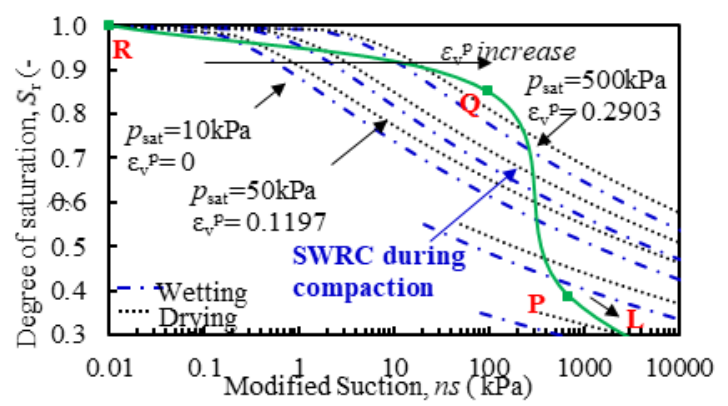

(b)

Fig. 2. General characteristics of model

\section{Volumetric behaviour of the model}

For modelling purposes, the volumetric yield surface is commonly presented by a series of hyperlines. In many models, these hyperlines are defined at constant suction [15]. This representation requires constant suction loading. Alternatively, Abeyrathne et al. [16] introduced the use of constant hyperlines to represent the volumetric yield surface, as shown in Figure 1. However, in the generalised MPK model, the hyperlines are converted to constant $S_{\mathrm{r}}$ lines. The advantage of using constant $S_{\mathrm{r}}$ lines include the possibility of natural transition to ATL $\left(S_{\mathrm{r}}=S_{\mathrm{r}}^{\mathrm{L}}\right)$ and NCL $\left(S_{\mathrm{r}}=1\right)$.

The part of the yield surface for $S_{\mathrm{r}}<S_{\mathrm{r}}^{\mathrm{L}}$, the soil is aggregated and the air phase can be considered continuous. Hence, it can be considered that a net stress approach (e.g., as used in BBM) is readily applicable. Therefore, for the dry side of ATL, the variation of the compression index $\lambda\left(S_{\mathrm{r}}\right)$ with $S_{\mathrm{r}}$ is given by:

$$
\lambda\left(S_{\mathrm{r}}\right)=\lambda_{\mathrm{L}}-k_{3}\left(S_{\mathrm{r}}-S_{\mathrm{r}}^{\mathrm{L}}\right)
$$

In addition, the nominal specific volume $\left(v_{\mathrm{o}}\right)$ is defined in terms of $S_{\mathrm{r}}$ as: 


$$
v_{\mathrm{o}}=v_{\mathrm{o}}^{\mathrm{L}}-k_{4}\left(S_{\mathrm{r}}-S_{\mathrm{r}}^{\mathrm{L}}\right)
$$

where, $\lambda\left(S_{\mathrm{r}}\right)$ is the compression index at constant $S_{\mathrm{r}}$ and $S_{\mathrm{r}}^{\mathrm{L}}$ is the degree of saturation on ATL. In particular, $\lambda_{\mathrm{L}}$ and $v_{\mathrm{o}}^{\mathrm{L}}$ arise from the definition of ATL $\left(v=v_{\mathrm{o}}^{\mathrm{L}}\right.$ $\left.-\lambda_{\mathrm{L}} \ln \left(p / p_{\mathrm{o}}\right)\right)$. Therefore, the specific volume $(v)$ on the volumetric yield surface can be written as:

$$
v=v_{\mathrm{o}}-\lambda\left(S_{\mathrm{r}}\right) \ln \left(p / p_{\mathrm{o}}\right)
$$

When $S_{\mathrm{r}}>S_{\mathrm{r}}^{\mathrm{L}} \quad$ (i.e., on the wet side of ATL), Equation (6) is not applicable. In this region, Bishop's effective stress is considered to be valid, since soil aggregates are not present and the air is trapped. The compression index $\lambda\left(S_{\mathrm{r}}\right)$ is, therefore, assumed to be constant with the value of the saturated soils $\lambda_{\text {sat }}$. The hardening rule od the proposed model is given by:

$$
\mathrm{d} \varepsilon_{\mathrm{v}}^{\mathrm{p}}=\left(\frac{\lambda_{\text {sat }}-k_{\text {sat }}}{v_{\text {sat }}}\right) \frac{\mathrm{d} p_{\text {sat }}}{p_{\text {sat }}}
$$

Where, $k_{\text {sat }}, v_{\text {sat }}$ and $p_{\text {sat }}$ are unloading/reloading coefficient, specific volume and net stress at saturation.

\section{Coupled hydraulic behaviour}

The amended SWRC of the MPK generalised model can be given as (see Kodikara et al. [13] for derivation):

$$
S_{\mathrm{r}}=\left(1+\frac{1}{m}\left(\frac{s^{*}}{a^{\mathrm{L}}}\right)^{\mathrm{n}}\right)^{-\mathrm{m}}
$$

Similar to the original Van Genuchten equation, the above model still has three parameters, $m$ (that defines from $S_{\mathrm{r}}^{\mathrm{L}}$ ) and $a^{\mathrm{L}}$ and $n$. The $a^{\mathrm{L}}$ is the modified air transition suction, and the parameter $n$ is considered to be a constant for a particular soil type. On the basis of available experimental evidence [17], it is considered that the inflexion point of the SWRC better represents ATL, which features the transition of the continuity of the water and air phases. It is normally considered that the air entry occurs close to saturation $\left(S_{\mathrm{r}}=1\right)$, whereas at ATL $S_{\mathrm{r}}$ will be lower, but will depend on the soil type. Typically, $S_{\mathrm{r}}^{\mathrm{L}}$ is between 0.85 and 0.95 for clayey soils, 0.80 and 0.85 for silt, and 0.65 and 0.80 for sand, depending on its particle size uniformity.

The hysteretic behaviour of SWRC is captured by two curves, namely the wetting curve and the drying curve. For wetting and drying, $m$ is considered as a constant, whereas the $n$ parameter and $a^{\mathrm{L}}$ are twofold for wetting and drying $\left(n_{\mathrm{w}}, n_{\mathrm{d}}, a_{\mathrm{w}}^{\mathrm{L}}\right.$ and $\left.a_{\mathrm{d}}^{\mathrm{L}}\right)$. Hence, the equations for the wetting and drying branches can be written as:

$$
S_{\mathrm{r}}=\frac{1}{\left(1+\frac{1}{m}\left(\frac{s^{*}}{a_{\mathrm{w}}^{\mathrm{L}}}\right)^{\mathrm{n}_{\mathrm{w}}}\right)^{\mathrm{m}}} \text { and } S_{\mathrm{r}}=\frac{1}{\left(1+\frac{1}{m}\left(\frac{s^{*}}{a_{\mathrm{d}}^{\mathrm{L}}}\right)^{\mathrm{n}_{\mathrm{d}}}\right)^{\mathrm{m}}}
$$

Therefore, assuming that $n$ is a constant, the change in the degree of saturation $\left(S_{\mathrm{r}}\right)$ along wetting and drying paths $(\mathrm{w} / \mathrm{d}$ ) can be expressed as:

$$
\mathrm{d} S_{\mathrm{r}}=C_{\mathrm{w}} \mathrm{d} s^{*}+D_{\mathrm{w}} \mathrm{d} a_{\mathrm{w}}^{\mathrm{L}} \text { and } \mathrm{d} S_{\mathrm{r}}=C_{\mathrm{d}} \mathrm{d} s^{*}+D_{\mathrm{d}} \mathrm{d} a_{\mathrm{d}}^{\mathrm{L}}
$$

where, $\quad C_{\mathrm{w} / \mathrm{d}}\left(=\frac{\partial S_{\mathrm{r}}}{\partial s^{*}}\right)_{a_{\mathrm{w} / \mathrm{d}}^{\mathrm{L}}}$ and $\quad D_{\mathrm{w} / \mathrm{d}}\left(=\frac{\partial S_{\mathrm{r}}}{\partial a_{\mathrm{w} / \mathrm{d}}^{\mathrm{L}}}\right)_{s^{*}}$ can be represented using hydraulic parameters $\left(a_{\mathrm{w} / \mathrm{d}}^{\mathrm{L}}, s^{*}\right)$ and material parameters $\left(m, n_{\mathrm{w} / \mathrm{d}}\right)$ as:

$$
\begin{gathered}
C\left(=\frac{\partial S_{\mathrm{r}}}{\partial s^{*}}\right)_{a_{\mathrm{w} / \mathrm{d}}^{\mathrm{L}}}=\frac{-n_{\mathrm{w} / \mathrm{d}}\left(s^{*}\right)^{\mathrm{n}_{\mathrm{w} / \mathrm{d}}-1}}{\left(a_{\mathrm{w} / \mathrm{d}}^{\mathrm{L}}\right)^{\mathrm{n}_{\mathrm{w} / \mathrm{d}}}} \frac{1}{\left(1+\frac{1}{m}\left(\frac{s^{*}}{a_{\mathrm{w} / \mathrm{d}}^{\mathrm{L}}}\right)^{\mathrm{n}_{\mathrm{w} / \mathrm{d}}}\right)^{\mathrm{m}+1}} \\
D\left(=\frac{\partial S_{\mathrm{r}}}{\partial a_{\mathrm{w} / \mathrm{d}}^{\mathrm{L}}}\right)_{s^{*}}=\frac{n_{\mathrm{w} / \mathrm{d}}\left(s^{*}\right)^{\mathrm{n}_{\mathrm{w} / \mathrm{d}}}}{\left(a_{\mathrm{w} / \mathrm{d}}^{\mathrm{L}}\right)^{\mathrm{n}_{\mathrm{w} / \mathrm{d}}+1}} \frac{1}{\left(1+\frac{1}{m}\left(\frac{s^{*}}{a_{\mathrm{w} / \mathrm{d}}^{\mathrm{L}}}\right)^{\mathrm{n}_{\mathrm{w} / \mathrm{d}}}\right)^{\mathrm{m}+1}}
\end{gathered}
$$

Since on the wet side of the LC curve, it is considered to follow the effective stress approach, and the effective stress is assumed to be equivalent to $p_{\text {sat }}$ and is equal to $p_{\mathrm{L}}+S_{\mathrm{r}}^{\mathrm{L}} s^{\mathrm{L}}$ for $v_{\text {sat }}$, therefore $a_{\mathrm{w}}^{\mathrm{L}}$ can be found as:

$$
a_{\mathrm{w}}^{\mathrm{L}}=\phi s^{\mathrm{L}}=\left(\frac{v_{\mathrm{sat}}-1}{v_{\mathrm{sat}}}\right) \frac{p_{\mathrm{o}}}{S_{\mathrm{r}}^{\mathrm{L}}}\left[e^{\left(\frac{v_{\mathrm{sat}}^{0}-v_{\mathrm{sat}}}{\lambda_{\mathrm{sat}}}\right)}-e^{\left(\frac{C_{4}-v_{\mathrm{sat}}}{\lambda_{\mathrm{L}}}\right)}\right]
$$

where, $v_{\text {sat }}$ is the specific volume on NCL for a particular $p_{\text {sat }}$, and $v_{\text {sat }}^{0}$ is the specific volume at nominal stress $p_{\mathrm{o}}$ along NCL.

\section{Material parameters of the model}

This paper utilises the material parameters obtained for the experimental data by Raveendiraraj [18], which include constant suction loading tests for compacted Spacewhite kaolin. The volumetric yield surface was generated using suction-controlled loading stress paths to estimate the 9 mechanical parameters. Of the 9 parameters, $\lambda_{\mathrm{L}}, k_{3}, v_{\mathrm{o}}^{\mathrm{L}}$, and $k_{4}$ can be found by generating the LWSBS from the available experimental data. The $k_{\mathrm{w}}, v_{\text {sat }}^{0}, \lambda_{\text {sat }}$, and $k_{\text {sat }}$ parameters were assumed, as there were no saturated loading/unloading (isotropic consolidation test) experiments. In addition, $S_{\mathrm{r}}^{\mathrm{L}}$ is taken as 0.85 . If constant $e_{\mathrm{w}}$ tests were undertaken (which are 
much easier and faster to perform), these parameters could be estimated in a similar fashion.

Table 1. Model parameters

\begin{tabular}{|c|c|c|c|}
\hline \multicolumn{4}{|c|}{ Raveendiraraj [18] } \\
\hline \multicolumn{2}{|c|}{ Mechanical behaviour } & \multicolumn{2}{c|}{ Hydraulic behavior } \\
\hline$\lambda_{\mathrm{L}}$ & 0.175 & $b$ & 5 \\
\hline$k_{3}$ & 0.23 & $\alpha_{\mathrm{ES}}$ & 0.6 \\
\hline$v_{\mathrm{o}}^{\mathrm{L}}$ & 2.38 & $\alpha_{1}$ & 0.63 \\
\hline$k_{4}$ & 1.3 & $\alpha_{2}$ & 0.57 \\
\hline$k_{\mathrm{w}}$ & 0.0005 & $\beta$ & 0.1 \\
\hline$v_{\text {sat }}^{0}$ & 2.4 & $X$ & 0.5 \\
\hline$k_{\mathrm{sat}}$ & 0.0012 & $n_{\mathrm{w}}$ & 1.45 \\
\hline$\lambda_{\text {sat }}$ & 0.181 & $n_{\mathrm{d}}$ & 1.35 \\
\hline$S_{\mathrm{r}}^{\mathrm{L}}$ & 0.85 & & \\
\hline
\end{tabular}

The other six parameters used for coupled hydraulic behaviour are $n, X, b, \alpha_{\mathrm{ES}}, \alpha_{\mathrm{o}}$, and $\beta$. Of these, $n$, $X, b$ are related to the SWRC measured at constant plastic volumetric strains $\varepsilon_{\mathrm{v}}^{\mathrm{p}}$ and the gradient of the ESL, $\alpha_{\mathrm{ES}}$, can be identified as the stabilised wetting drying gradient on the $v, v_{\mathrm{w}}$ plane. In addition, $\alpha_{1}, \alpha_{2}$ and $\beta$ can be found using wetting/drying experiments.

\section{Behaviour of soil water retention curves with $a_{\mathrm{w}}^{\mathrm{L}}$}

Figure 3(a) exhibits the SWRCs for several plastic strains $\left(\varepsilon_{\mathrm{v}}^{\mathrm{p}}=0 \quad\left(a_{\mathrm{w}}^{\mathrm{L}}=1.64 \mathrm{kPa}\right), 0.1197\left(a_{\mathrm{w}}^{\mathrm{L}}=6.06 \mathrm{kPa}\right)\right.$, $0.2903\left(a_{\mathrm{w}}^{\mathrm{L}}=31.34 \mathrm{kPa}\right)$ ) corresponding to some LC curves in Figure 3(b) for a constant $m(0.055)$, and $n_{\mathrm{w} / \mathrm{d}}(1.45$ and 1.35$)$. The drying air transition (AT) value $\left(a_{\mathrm{d}}^{\mathrm{L}}=10^{\left(\mathrm{X}+\log \left(a_{\mathrm{w}}^{\mathrm{L}}\right)\right)}\right)$ is a function of the wetting AT value, and the distance between the two curves is assumed to be constant for a particular soil, as noted earlier. It should also be noted that the SWRC in the current model manifests a smaller gradient than the conventional SWRC. This occurs due to the possible accumulation of $\varepsilon_{\mathrm{v}}^{\mathrm{p}}$ during wetting and subsequent drying as applicable to the so-called major wetting and drying curves.

Another set of partial SWRCs can be defined considering the LC curves derived on the nominal stress contour, as shown in Figure 4. Considering the initial degree of saturation (i.e., $\left(S_{\mathrm{r}}\right)_{\text {Initial }}=0.75,0.65,0.55$, 0.45 and 0.35 ), a set of loading collapse yield curves can be defined by hinging on the nominal stress contour instead of hinging on NCL. The required air transition $a_{\mathrm{w}}^{\mathrm{L}}$ can be found by extrapolating the $a_{\mathrm{w}}^{\mathrm{L}}$ (i.e., $1.64 \mathrm{kPa}$ ) associated with the complete SWRC at $p=10 \mathrm{kPa}$. For one LC curve in Figure 4(b), a partial wetting curve and a drying curve can be obtained, as shown in Figure 4(a). These partial SWRC curves occur because we considered them up to the $S_{\mathrm{r}}$ corresponding nominal stress, as shown in Figure 4.

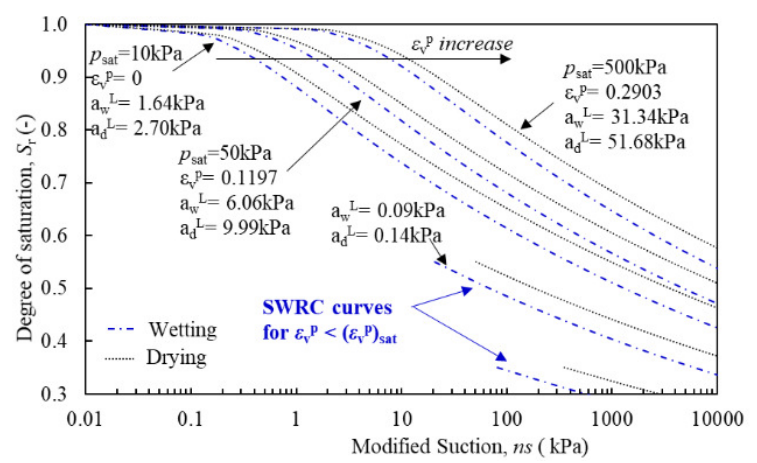

(a)

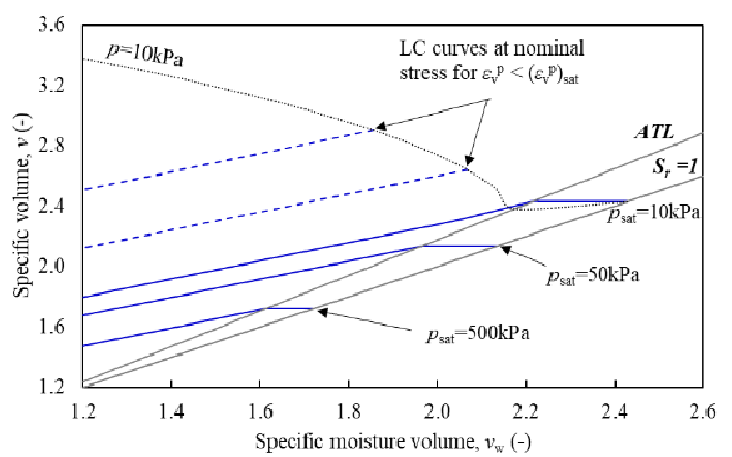

(b)

Fig. 3. Loading collapse yield curves of the model

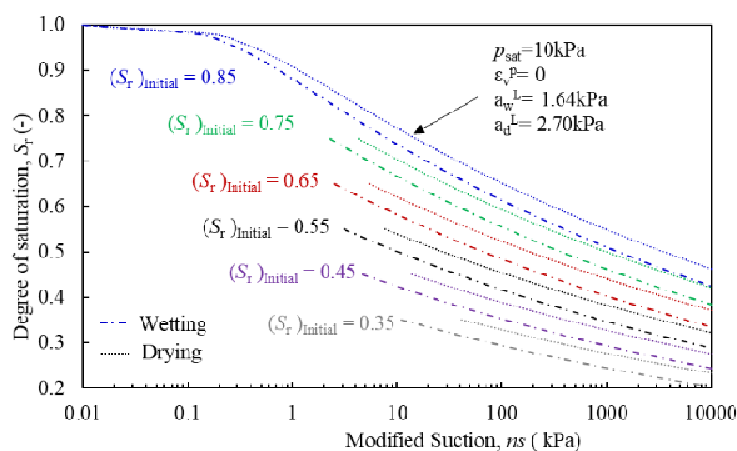

(a)

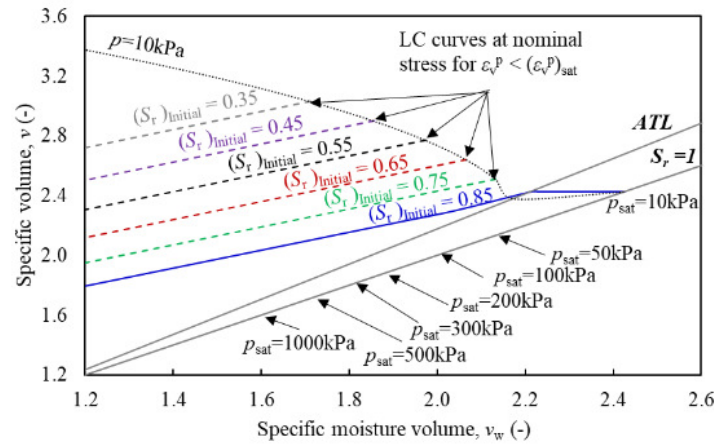

(b)

Fig. 4. Loading collapse yield curves of the model 


\section{Experimental validation}

Raveendiraraj [18] published a series of sophisticated experimental results for various combinations of isotropic loading, unloading, wetting and drying performed on compacted kaolin. For the validation of the MPK generalised model, test A9 is used in this paper. Initial equalisation was performed to reach the targeted initial stress values, but unfortunately no measurements were made during this phase. If the figures were available, that process could also be modelled with the current model. Therefore, only subsequent stress paths after equalisation are modelled here.

Table 2. Experimental validation A9

\begin{tabular}{|l|l|l|l|l|}
\hline \multicolumn{2}{|l|}{} & $\begin{array}{l}\text { Net } \\
\text { stress } \\
(p / \mathrm{kPa})\end{array}$ & $\begin{array}{l}\text { Suction } \\
(s / \mathrm{kPa})\end{array}$ \\
\hline A & B & Loading & $10 \rightarrow 200$ & 300 \\
\hline B & C & Unloading & $200 \rightarrow 10$ & 300 \\
\hline C & D & Wetting & 10 & $300 \rightarrow 10$ \\
\hline D & E & Drying & 10 & $10 \rightarrow 300$ \\
\hline E & F & Loading & $10 \rightarrow 375$ & 300 \\
\hline
\end{tabular}

As shown in Figure 5, the sample was equalised at mean net stress of $10 \mathrm{kPa}$ and suction of $300 \mathrm{kPa}$ (state $A$ in Figure 5) prior to the loading, unloading, wetting, drying, and loading stress paths (see Table 2). The sample was loaded to a mean net stress of $200 \mathrm{kPa}$ under a suction of $300 \mathrm{kPa}$ (i.e., stress path $A B$ ), where the model predicted yielding after $120 \mathrm{kPa}$. Subsequently, the sample was unloaded to the mean net stress of $10 \mathrm{kPa}$ at the suction of $300 \mathrm{kPa}$ (i.e., stress path $B C$ ). As shown in Figure 5(b) and Figure 5(c), the simulation of $v$ and $S_{\mathrm{r}}$ with $p$ then follows the experimental results and indicates reasonable agreement with the experimental results.

Utilising the environmentally-stabilised line concept, although the wetting drying behaviour of A9 is modelled, a detailed mathematical description is not given in this paper (see Kodikara et al. [13] for derivation). At state $\mathrm{C}$, for the first wetting cycle, $\alpha_{1}$ of $0.63\left(>\alpha_{\mathrm{ES}}=0.6\right)$ was selected, as shown in Figure 5(a), where simulated and experimental paths are reasonably consistent. During the subsequent constant net stress drying path (i.e., stress path $D E), \alpha_{2}=0.57\left(<\alpha_{\mathrm{ES}}=\right.$ 0.6), following the stress paths, as shown in Figure 5(a). The sample was then further loaded simultaneously to mean net stress of $375 \mathrm{kPa}$ at the suction of $300 \mathrm{kPa}$ in the stress path $E F$.

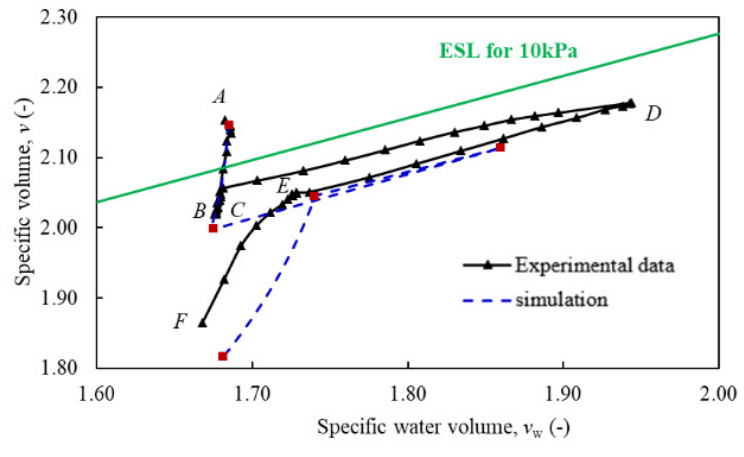

a)

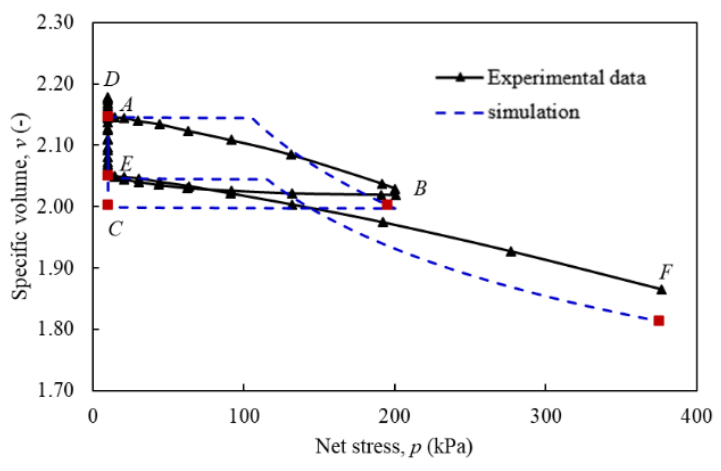

b)

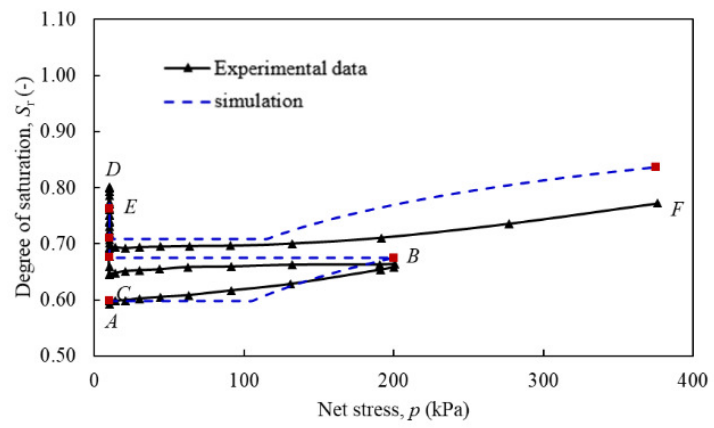

c)

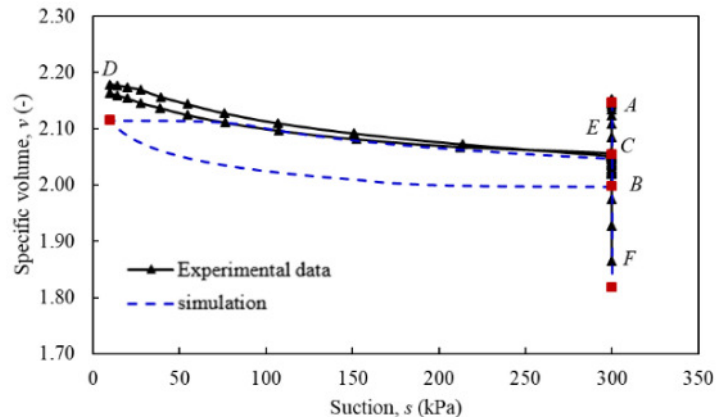

d)

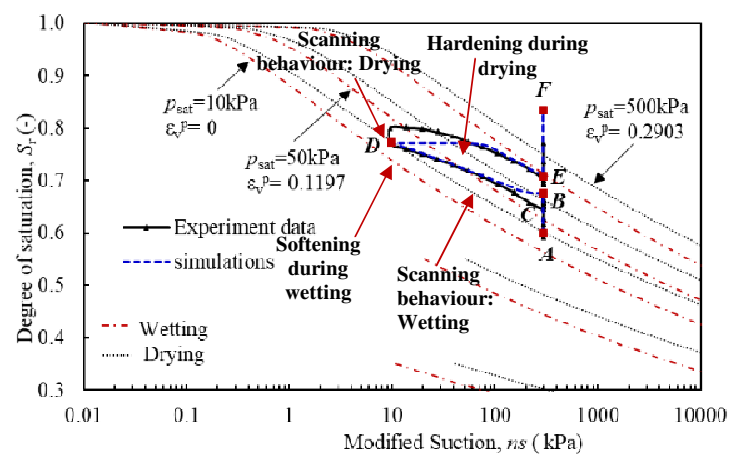

Fig. 5. Model simulations of test A9 (a) $v, v_{w}$ plane; (b)

$v, p$ plane ; (c) $S_{\mathrm{r}}, p$ plane; (d) $v, s$ plane; (e) $S_{\mathrm{r}}, s$ plane. 
As apparent in_Figure 5(e), during stress path CD, the simulation exhibits a scanning behaviour followed by a yielding behaviour while crossing several major wetting curves. During the subsequent drying (i.e., stress path DE), similar behaviour is apparent. Hence, it can be clearly seen that the plastic volumetric-dependent SWRC is capable of capturing the hydraulic response of the unsaturated soil qualitatively.

\section{Major drying and wetting curves}

As indicated earlier, the common practice for developing major drying and wetting curves is to saturate the specimen from the compacted state and then dry it to high suctions. The drying process defines the major drying curve. When the specimen is wetted from a dried state, major wetting is obtained. Here we highlight that the so-called major drying and wetting curves can cross a number of SWRCs defined based on the constant plastic strains due to changes in plastic strain with drying and wetting. Of course, the plastic strain change depends on the soil reactivity (more clayey or sandy), as reflected by the material parameters of the model.

In Figure 6, we simulate the development of major drying and wetting curves corresponding to $10 \mathrm{kPa}$ mean net stress using the data for kaolin from reference test A9 noted earlier. State $\mathrm{C}$ refers to the unloaded state after compaction to State B from the initial state A. The soil is then wetted to full saturation, as shown in path $\mathrm{CD}$, signifying the saturation process. Subsequently, the soil is dried to high suction, as shown path DEF, which can be considered as a major drying curve. As this simulation shows, the plastic volumetric strain increases along the major drying path, highlighting that plastic hardening takes place during first drying. When the soil is wetted from this position, it follows the path FGH, which can be considered as a major wetting curve, and softening again takes place with reduction of $\varepsilon_{\mathrm{v}}^{\mathrm{p}}$. This also means that the LC curve shifts rightwards as $\varepsilon_{\mathrm{v}}^{\mathrm{p}}$ increases with drying and leftwards as $\varepsilon_{\mathrm{v}}^{\mathrm{p}}$ decreases with wetting.

In addition, it is also clear that during initial saturation (path CD), soil undergoes plastic softening (or reduction in $\varepsilon_{\mathrm{v}}^{\mathrm{p}}$ ). Similarly, the common initialisation process in suction control tests (where the soil is wetted to achieve a target suction) can also induce plastic strain changes. Furthermore, during subsequent dry/wet cycles the measured SWRC can shift with plastic strain changes until they stabilise to constant plastic strain SWRCs where the soil is considered environmentally stabilised, as defined in the model. This aspect is simulated considering 4 dry/wet cycles as shown in Figure 6, where SWRC at the $4^{\text {th }}$ cycle approaches close to the environmentally-stabilised state with a constant $\varepsilon_{\mathrm{v}}^{\mathrm{p}}$. This process of SWRC development can also occur differently when the operating mean net is changed. Under these circumstances, the definitions of major drying and wetting curves need to considered, taking these factors into account.

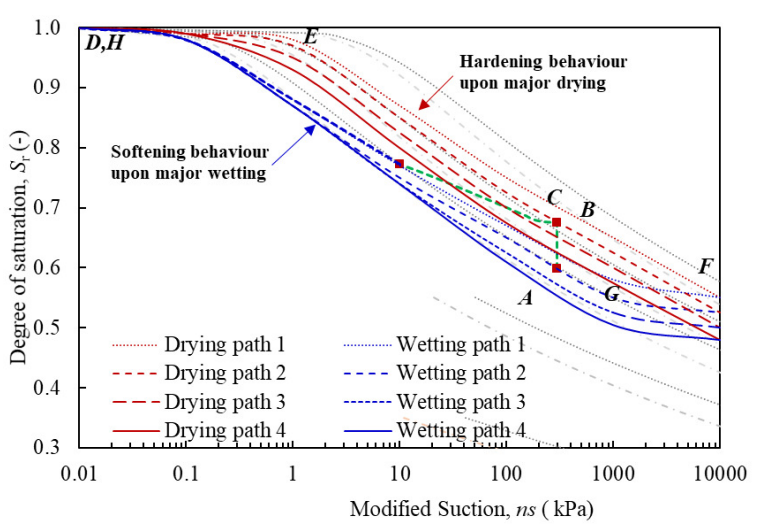

Fig. 6. Model simulations of major wetting and major drying paths

\section{Conclusions}

Within the constitutive framework of the MPK model developed by Kodikara et al. [13], hydraulic behaviour is explained using the SWRCs dependent on volumetric plastic strains. For a given plastic strain, the SWRC is linked with a particular LC curve. During loading, if plastic strains occur due to yielding, both SWRC and LC curves can shift. Similarly, both these curves can shift if plastic strains occur during drying and wetting at a constant mean net stress. These behaviours were validated by the simulation of the loading/ unloading/ drying/ wetting paths followed in a laboratory experiment. In addition, the evolution of commonly considered major drying and wetting curves was simulated, highlighting that they may not be bounding curves as commonly interpreted, but are observations of the test conditions.

\section{References}

1. S.L. Barbour, Can. Geotech. J., 35, 5, 873-894 (1998)

2. D.G. Fredlund and H. Rahardjo, Soil mechanics for unsaturated soils (John Wiley \& Sons, 1993)

3. D.G. Toll, I. Bertolini, and J.D. Asquith, Proceedings of the XVII ECSMGE (2019)

4. D. Gallipoli, S. Wheeler, and M. Karstunen, Géotechnique, 53, 1, 105-112 (2003)

5. M. Morvan, H. Wong, and D. Branque, Can. Geotech. J., 48, 12, 1855-1869 (2011)

6. D. Mašín, Int. J. Numer. Anal. Methods Geomech., 34, 1, 73-90 (2010)

7. M. Nuth, and L. Laloui, in Unsaturated Soils: Advances In Geo-Engineering (CRC Press-Taylor \& Francis Group, Boca Raton, 2008)

8. A.-N. Zhou et al., Computers and Geotechnics, 43, 111-123 (2012)

9. S. Wheeler, R. Sharma, and M. Buisson, Géotechnique, 53, 1, 41-54 (2003) 
10. M. Lloret-Cabot et al., Acta Geotechnica, 13, 15-37 (2018)

11. M.T. Van Genuchten, Soil Sci. Soc. America J., 44, 5, 892-898 (1980)

12. M. Lloret-Cabot et al., Can. Geotech. J., 51, 12, 1423-1437 (2014)

13. J. Kodikara, C. Jayasundara, and A. Zhou, A generalised constitutive model for unsaturated compacted soils considering wetting/drying cycles and environmentally stabilised line. 2019 (under review).

14. A. Tarantino, and E. De Col, Géotechnique, 58, 3, 199-213 (2008)

15. E.E. Alonso, A. Gens, and A. Josa, Géotechnique, 40, 3, 405-430. (1990)

16. A. Abeyrathne, V. Sivakumar, and J. Kodikara, Can. Geotech. J. (2019) (In press).

17. A. Dexter, Geoderma, 120, 3-4, 227-239 (2004)

18. tA. Raveendiraraj, Coupling of mechanical behaviour and water retention behaviour in unsaturated soils (University of Glasgow, Department of Civil Engineering, United Kingdom, 2009) 